\title{
Interactive comment on "The Subhercynian Basin: An example of an intraplate foreland basin due to a broken plate" by David Hindle and Jonas Kley
}

\section{Brian Horton (Referee)}

horton@jsg.utexas.edu

Received and published: 10 February 2021

Overview. The manuscript identifies the important issue of narrow but deep basins associated with isolated basement-involved contractional structures in intraplate settings far away from major orogenic belts. The modeling approach invokes multiple discrete elastic breaks that are defined in the flexural model by prescribing much-reduced effective elastic thicknesses for narrow vertical zones at multiple locations along a crosssection profile. The inclusion of these prescribed weaknesses allows for the observed thrust-generated loads to accurately account for the observed distribution of Upper Cretaceous sedimentary fill.

Fault spacing. The short wavelength (narrow width) of the Subhercynian Basin may be 
explained by strict elastic flexure with prescribed weaknesses, but also could be largely the result of the position of a series of anticlines (the related Huy, Fallstein, and Haken or "HFH" anticlines) on the distal northern side of the Subhercynian Basin. These HFH anticlines are parallel to the Harz Mountains and its bounding thrust, the Harz Northern Boundary Fault. As shown in Fig. 1 map, the Subhercynian Basin is rather narrow (roughly $12 \mathrm{~km}$; for example: the distance from the bounding thrust to Dardesheim) over most of its $\sim 80 \mathrm{~km}$ strike length, but is considerably wider (up to $\sim 30 \mathrm{~km}$; for example: the distance from the bounding thrust to Braunschweig) at the western end, beyond the extent of the HFH anticlines. This discrepancy would suggest that the presence or absence of the HFH anticlines are largely controlling the observed width of the basin. In turn, this suggests that the overall spacing of successive thrust faults (namely the Harz Northern Boundary Fault and the fault(s) responsible for the thrustgenerated HFH anticlines) is largely governing the width of the Subhercynian Basin. Given a map-view spacing of $10-15 \mathrm{~km}$ and a moderate dip $\left(45-60^{\circ}\right)$ of reverse/thrust faults, these faults may merge at depth into a 10-15 km deep decollement, such that the base of the fault responsible for the HFH anticlines would be, more or less, directly beneath the surface trace of the Harz Northern Boundary Fault, a geometry similar to that depicted in Fig $3 b$ cross section (Kley et al. 2008).

Fault timing. Recognizing that the geologic record studied here appears to represent a relatively short-lived pulse of deformation and associated sediment accumulation, it is still worth considering whether there are any discernible temporal trends in basement faulting and sedimentation. For example, what is the relative timing between the Harz Northern Boundary Fault (HNBF) and the Huy, Fallstein, and Haken ("HFH") anticlines? Are the HFH anticlines related to a single structure, or potentially three separate structures that merged with continued displacement. Are the fault(s) responsible for the HFH anticlines geometrically linked at depth with the subsurface continuation of the HNBF? Could they be considered a splay of similar geometry as the HNBF but with much more limited displacement? Although more speculative, could the HFH anticlines be related to a flexural bulge? Given the wavelength/spacing, this would require rather low values 
of effective elastic thickness.

Flexural modeling. The flexural modeling centers on the case of a broken plate in which several thrust structures span a large segment of the crust. For many similar cases, the size of the shortening-induced topographic load is too small to account for the relatively deep basins observed adjacent to the intraforeland uplift. One possible option to reconcile this discrepancy is to allow for additional faults, such that individual broken plates (i.e., broken on both ends) could more readily tilt (McQueen and Beaumont, 1989, Mechanical models of tilted block basins, AGU Geophysical Monograph 48), thus creating larger than expected accommodation space. Also, how would the model predictions be affected by using moderately dipping $\left(45-60^{\circ}\right)$ rather than vertical weaknesses or elastic breaks? As a final side comment, it is interesting to see the references to the 1940s work by Gunn. Much of the post-plate tectonics elastic flexural modeling of foreland basins was based on Hetenyi, M., 1946, Beams on elastic foundation: The University of Michigan Press, $257 \mathrm{p}$.

Interactive comment on Solid Earth Discuss., https://doi.org/10.5194/se-2020-185, 2020.
SED

Interactive

comment 